\title{
Misuse of Topical Corticosteroids for Cosmetic Purpose in Antananarivo, Madagascar
}

\author{
F. A. Sendrasoa, I. M. Ranaivo, M. Andrianarison, O. Raharolahy, N. H. Razanakoto, \\ L. S. Ramarozatovo, and F. Rapelanoro Rabenja \\ Department of Dermatology, University Hospital Joseph Raseta Befelatanana, Antananarivo, Madagascar \\ Correspondence should be addressed to F. A. Sendrasoa; nasendrefa@yahoo.fr
}

Received 11 April 2017; Accepted 19 July 2017; Published 21 August 2017

Academic Editor: Pankaj K. Bhavsar

Copyright (c) 2017 F. A. Sendrasoa et al. This is an open access article distributed under the Creative Commons Attribution License, which permits unrestricted use, distribution, and reproduction in any medium, provided the original work is properly cited.

\begin{abstract}
This cross-sectional study was conducted in Antananarivo, Madagascar, from June to September 2012. We aim to evaluate the misuse of TC on the face for cosmetic purpose and the adverse effects due to its application. A questionnaire-based analysis was done among females who use topical corticosteroids on the face for cosmetic purpose. Of the 770 women questioned, 384 (49,8\%) used topical corticosteroids for cosmetic purpose whose mean age was 38 years (range 16-73 years). Two hundred and sixty-one females (68\%) used TC combined with handcrafted cosmetics, and $123(32 \%)$ used TC alone. "Pandalao," which contains salicylic acid, peppermint oil, lanolin, powder of Juanes de Vigo (mercury powder), and Vaseline, is the most handcrafted cosmetic combined with TC in our study (used by $29,4 \%$ respondents). Only one $(0,26 \%)$ had obtained the TC by physician's prescription, 234 (61\%) from cosmetic retailers, 92 (23\%) directly from local pharmacies, 49 (12\%) from beauticians, and 15 (4\%) from unspecified sources. Lightening of skin color was the main reason for using TC in $44,8 \%$ of respondents in the absence of any primary dermatosis. Pigmentation disorders $(63,2 \%)$ and cutaneous atrophy $(52,1 \%)$ were the most adverse effects noted.
\end{abstract}

\section{Introduction}

Topical corticosteroids (TC) have been used for more than six decades to treat various dermatological disorders due to their wide range of action $[1,2]$. As several countries where potent TC are easily available over-the-counter at a low price, misuse has been noticed among the general population, producing many adverse effects $[3,4]$. To our knowledge, in spite of being a common problem, no study has investigated the misuse of topical corticosteroid products in Madagascar. This study was conducted among females living in Antananarivo, Madagascar, to assess the frequency of TC misuse, the reasons behind it, and the most common adverse effects resulting from it.

\section{Methodology}

A cross-sectional study was conducted from June to September 2012 in Antananarivo which is the capital of Madagascar.
Investigations were done in municipal markets, popular neighborhoods in Antananarivo, pharmacies, beauty salons, and supermarkets.

A questionnaire-based analysis was done among females who use topical corticosteroids alone or associated with other products, on the face for cosmetic purpose. Of the 770 women questioned, 384 respondents were included. The following data were collected: characteristics of study participants (age, educational level), class of topical corticosteroids, reasons of use, adverse effects, and conditions of issue. A full skin examination was performed to detect any condition related to abuse of TC. Most of the diagnoses were exclusively clinical and were based on the typical, classical features.

Patient's attitudes toward the side effects were also evaluated in our study.

Statistical Analyses. Data was analysed by "R" software created by Robert Gentleman and Ross Ihaka, in the Department of Statistics at the University of Auckland in New Zealand. 
TABLE 1: Total number of respondents' age group and educational level.

\begin{tabular}{lcc}
\hline & Number of patients (\%) & $p^{*}$ \\
\hline Age group (years) & & \\
$15-24$ & $21(5,4)$ & \\
$25-34$ & $83(21,6)$ & $<0,05^{*}$ \\
$35-44$ & $137(35,6)$ & \\
$45-54$ & $101(26,3)$ & \\
$\geq 55$ & $42(10,9)$ & \\
Educational level & & \\
Illiterate & $132(34,4)$ & \\
Primary school & $97(25,2)$ & \\
Secondary school & $81(21)$ & \\
High school & $46(12)$ & \\
University & $28(7,3)$ & \\
\hline
\end{tabular}

${ }^{*}$ The use of TC is common in the age group of 35-44 years and illiterate females.

TABLE 2: Various classes of TC used by patients and duration use.

\begin{tabular}{lcc}
\hline & $\begin{array}{c}\text { Number of } \\
\text { patients } \\
(\%)\end{array}$ & $p^{*}$ \\
\hline Various classes & & \\
Class I (superpotent) & $4(1)$ & \\
Class II (potent) & $96(25)$ & \\
Class III (least potent) & $23(6)$ \\
Handcrafted cosmetic containing TC & $261(68)$ & \\
Duration use & & \\
3 weeks-3 months & $41(10,6)$ \\
3 months-11 months & $50(13)$ \\
1-5 years & $184(48)$ \\
6-10 years & $47(12,2)$ \\
$>10$ years & $62(16,1)$ & \\
\hline
\end{tabular}

${ }^{*}$ Common duration use of TC is between 1 and 5 years.

\section{Results}

One hundred and thirty-seven females $(35,6 \%)$ in the age group of 35-44 years used TC (Table 1) and 34,4\% were illiterate.

Of the total 384 respondents, 261 (68\%) used TC combined with handcrafted cosmetics, and 123 (32\%) used TC alone. All females enrolled into study had a history of using topical corticosteroids for at least 3 weeks. The various classes of TC used by patients and the duration use were detailed in Table 2. "Pandalao" is the most handcrafted cosmetic combined with TC in our study (used by $29,4 \%$ respondents), which contains salicylic acid, peppermint oil, lanolin, powder of Juanes de Vigo (mercury powder), and Vaseline.

Of the 384 respondents, only one $(0,26 \%)$ had obtained the TC on physician's prescription, 234 (61\%) from cosmetic retailers, 92 (23\%) directly from local pharmacies, 49 (12\%) from beauticians, and 15 (4\%) from unspecified sources.
TABLE 3: Dermatological adverse effects.

\begin{tabular}{lcc}
\hline & Number of patients (\%) & $p^{*}$ \\
\hline None & $5(1,3)$ & \\
Pigmentation disorders & $243(63,2)$ & $<0,05^{*}$ \\
Cutaneous atrophy & $204(53,1)$ & \\
Steroid induced erythema & $202(52,6)$ & \\
Steroid dependency & $161(41,9)$ & \\
Hirsutism & $80(20,8)$ & \\
Contact dermatitis & $76(19,8)$ & \\
Acne & $66(17,1)$ & \\
Stretch marks & $19(5)$ & \\
Other adverse effects & $12(3,1)$ & \\
\hline
\end{tabular}

${ }^{*}$ Pigmentation disorders $(63,2 \%)$ were the most adverse effects noted.

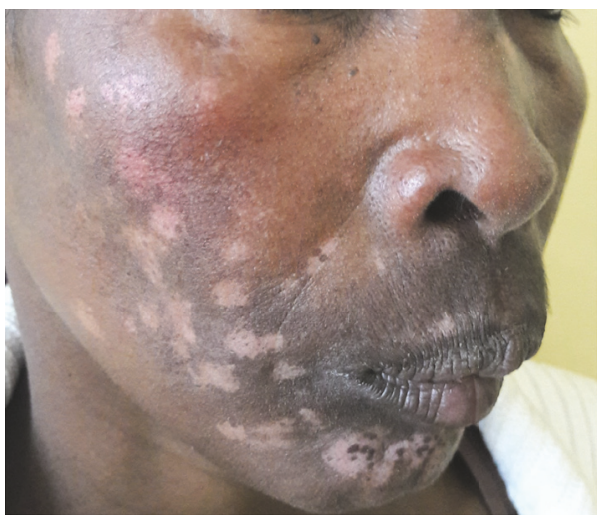

FIGURE 1: Steroid induced hypopigmentation.

One hundred and twenty-two respondents prepared themselves compositions containing topical corticosteroids, $52 \%$ used $15 \mathrm{~g}$ of TC per month, 23\% used 22,5 g, and 5\% used 30 g per month.

Lightening of skin color was the main reason for using TC in $44,8 \%$ of respondents in the absence of any primary dermatosis.

Only $5(1,3 \%)$ respondents did not present dermatological adverse effects of TC. The dermatological adverse effects of TC are listed in Table 3. Pigmentation disorders and cutaneous atrophy were the most adverse effects noted. Other adverse effects were steroid induced erythema, steroid dependency, hirsutism, and acne. Photographs representing some of the adverse effects are shown in Figures 1-4.

Only $13 \%$ of topical corticosteroids users intended to seek for dermatological care following cutaneous side effects. The cost of dermatological care was not affordable according to 152 respondents $(45,2 \%)$ and $84(25 \%)$ were convinced of the product's effectiveness.

\section{Discussion}

Our study shows that Malagasy women do not hesitate to use topical corticosteroids on the face for cosmetic purpose. 


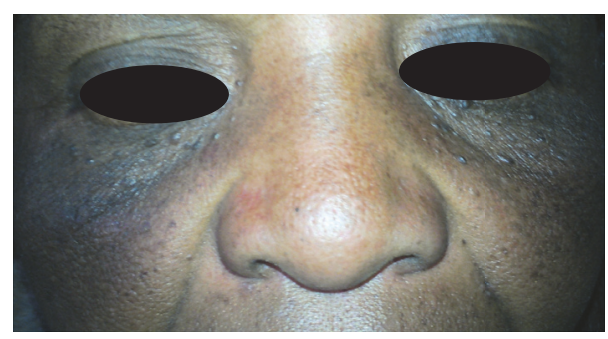

FIGURE 2: Steroid induced hyperpigmentation.

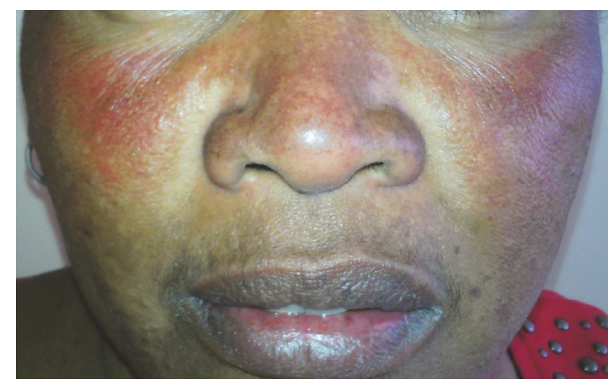

FIgURE 3: Erythema induced by topical corticosteroids.

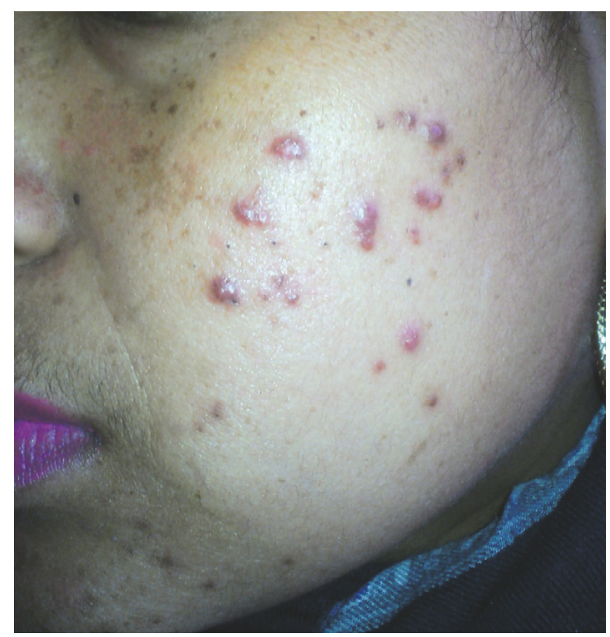

Figure 4: Steroid acne.

Malagasy purchasing power was limited to buy luxury cosmetics. This may explain the misuse of topical corticosteroids which is affordable. Potent topical corticosteroids were the most used. We conducted our study only in women because facial care is not yet daily habits for Malagasy men.

The first TC was introduced to the world of dermatology in 1952 by Sulzberger and Witten [1]. TC are principally used for their anti-inflammatory, antiproliferative, and immunosuppressive properties [2]. These properties confer upon them the ability to cure a wide variety of disorders.

Misuse of TC appears to be a common problem, as reported by many studies in India, China, Iraq, and Senegal
[3-9]. Like these countries [10], in Madagascar, most TC are available at throwaway prices since they come under drug control price order and they are mostly sold as overthe-counter products. This gives rise to multiple problems. However, most developed countries restrict the sales of TC strictly by prescription, because they should be used judiciously, for appropriate indications and duration. As in many African countries, Malagasy women face pressure to lighten their skin due to the widespread social perception that light skin is considered more attractive and reflective of high social status $[11,12]$.

The facial skin is vulnerable by TC because the facial skin is thinner than the skin of most other parts of the body. This results in increased percutaneous absorption of drugs. The sebaceous glands on the face are larger than elsewhere, and there is an increased tendency to sweating particularly in tempered and humid climates as is prevalent in most parts of Madagascar. Hence, it is more liable to the ill-effects of environmental factors such as sunlight and pollution, friction due to cleaning and rubbing, and application of cosmetics and drugs such as TC.

As in Accra Ghana [13], pigmentation disorders were the commonest adverse effects in our study. People with types IV to VI (like Malagasy people) are particularly affected by hypopigmentation; however, it is not noticed frequently in very light skinned individuals [14]. This difference may be related also to compositions used. In India where Panderm Plus Cream and Kligman's formula were widespread, the commonest adverse effect was acne $[7,15,16]$. In China, Lu et al. show that dermatitis and acne were the widest adverse effects [4].

Cutaneous atrophy after TC use is quite common; it was the second adverse effect observed in our result. Atrophic changes can affect both epidermis and dermis. Microscopic degenerative changes in epidermis are evident following 3-14 days of treatment. TC induce resorption of mucopolysaccharide ground substance in the dermis. Repeated use in the same area causes epidermal thinning and changes in connective tissue of dermis leading to lax, transparent, wrinkled, and shiny skin along with striae, fragility, and prominence of underlying veins. The loss of connective tissue support for dermal vasculature results in erythema, telangiectasia, and purpura [17]. Degree of skin atrophy is influenced by age, body site, potency, and presence of occlusion. Furthermore, systemic adverse effects from TC, which were not evaluated in our study, have also been described and they are more likely to develop when highly potent TC are used for prolonged periods on thin skin like facial skin or on raw surfaces $[17,18]$.

"Pandalao" which contains powder of Juanes de Vigo (mercury powder) is the most handcrafted cosmetic combined with TC in our study. The toxicity of mercury has been well known; the main adverse effect of the inorganic mercury is kidney damage [19]. Mercury may also cause skin rashes, skin discoloration, and scarring, as well as a reduction in the skin's resistance to bacterial and fungal infections $[3,20]$. Distribution of mercury containing creams and soaps should be banned in Madagascar like in European Union and numerous African nations [21, 22]. 


\section{Conclusion}

Our study revealed that misuse of topical corticosteroids is an important public health problem where several sectors were involved. TC are sold in cosmetic retailers and do not need prescription in pharmacies. The over-the-counter use of TC has a psychological impact on the user; no restriction use of TC ensures users about the safety of this product. In addition, misuse of TC shows that the supply channel of this product is defective and illegal in Madagascar. A task force against TC abuse should be formed in Madagascar, which seeks to raise public awareness, run media campaigns, form study for doctors, highlight the problem in journals, and meet with central and state authorities.

\section{Conflicts of Interest}

The authors declare that there are no conflicts of interest regarding the publication of this paper.

\section{References}

[1] M. B. Sulzberger and V. H. Witten, "The Effect of Topically Applied Compound F in Selected Dermatoses," Journal of Investigative Dermatology, vol. 19, no. 2, pp. 101-102, 1952.

[2] T. H. Rindani, "Topical action of steroid hormones on inflammation," Archives Internationales De Pharmacodynamie Et De Therapie, vol. 99, pp. 467-473, 1954.

[3] B. Ladizinski, N. Mistry, and R. V. Kundu, "Widespread use of toxic skin lightening compounds: Medical and psychosocial aspects," Dermatologic Clinics, vol. 29, no. 1, pp. 111-123, 2011.

[4] H. Lu, T. Xiao, B. Lu et al., "Facial corticosteroid addictive dermatitis in Guiyang City, China," Clinical and Experimental Dermatology, vol. 35, no. 6, pp. 618-620, 2010.

[5] Z.-H. Liu and X.-H. Du, "Quality of life in patients with facial steroid dermatitis before and after treatment," Journal of the European Academy of Dermatology and Venereology, vol. 22, no. 6, pp. 663-669, 2008.

[6] M. A. Al-Dhalimi and N. Aljawahiry, "Misuse of topical corticosteroids: A clinical study in an Iraqi hospital," Eastern Mediterranean Health Journal, vol. 12, pp. 847-852, 2006.

[7] A. Saraswat, K. Lahiri, M. Chatterjee et al., "Topical corticosteroid abuse on the face: A prospective, multicenter study of dermatology outpatients," Indian Journal of Dermatology, Venereology and Leprology, vol. 77, no. 2, pp. 160-166, 2011.

[8] S. B. Verma, "Sales, status, prescriptions and regulatory problems with topical steroids in India," Indian Journal of Dermatology, Venereology and Leprology, vol. 80, no. 3, pp. 201-203, 2014.

[9] A. Mahé, F. Ly, G. Aymard, and J. M. Dangou, "Skin diseases associated with the cosmetic use of bleaching products in women from Dakar, Senegal," British Journal of Dermatology, vol. 148, no. 3, pp. 493-500, 2003.

[10] A. Coondoo, "Topical corticosteroid misuse: The Indian Scenario," Indian Journal of Dermatology, vol. 59, no. 5, pp. 451-455, 2014.

[11] P. Del Giudice and P. Yves, "The widespread use of skin lightening creams in Senegal: A persistent public health problem in West Africa," International Journal of Dermatology, vol. 41, no. 2, pp. 69-72, 2002.

[12] A. E. Ahmed and M. E. Hamid, "Use of Skin-Whitening Products by Sudanese Undergraduate Females: a Survey," Journal of
Racial and Ethnic Health Disparities, vol. 4, no. 2, pp. 149-155, 2017.

[13] M. Lartey, F. D. Krampa, M. Abdul-Rahman et al., "Use of skin-lightening products among selected urban communities in Accra, Ghana," International Journal of Dermatology, vol. 56, no. 1, pp. 32-39, 2017.

[14] U. R. Hengge, T. Ruzicka, R. A. Schwartz, and M. J. Cork, "Adverse effects of topical glucocorticosteroids," Journal of the American Academy of Dermatology, vol. 54, no. 1, pp. 1-15, 2006.

[15] A. Jha, R. Sinha, and S. Prasad, "Misuse of topical corticosteroids on the face: A cross-sectional study among dermatology outpatients," Indian Dermatology Online Journal, vol. 7, no. 4, p. 259, 2016.

[16] S. B. Verma, "Topical corticosteroid misuse in India is harmful and out of control," BMJ, vol. 351, Article ID h6079, 2015.

[17] J. Berth-Jones, “Topical therapy," in Rooks Textbook of Dermatology, T. Burns, S. Breathnach, N. Cox, and C. Griffiths, Eds., vol. 1, pp. 1-73, Blackwell Science Ltd., UK, 8th edition, 2010.

[18] C. R. Srinivas and C. Lakshmi, "Principles of topical therapy in dermatology," in IADVL Textbook of Dermatology, R. G. Valia and A. R. Valia, Eds., pp. 1591-1618, Bhalani Publishing House, Mumbai, India, 3rd edition, 2008.

[19] IPCS, "Elemental mercury and inorganic mercury compounds: human health aspects," Geneva, World Health Organization, International Programme on Chemical Safety (Concise International Chemical Assessment Document 50, 2003, http:// www.who.int/entity/ipcs/publications/cicad/en/cicad50.pdf).

[20] A. S. Boyd, D. Seger, S. Vannucci, M. Langley, J. L. Abraham, and L. E. King, "Mercury exposure and cutaneous disease," Journal of the American Academy of Dermatology, vol. 43, no. 1, pp. 8190, 2000.

[21] C. M. Glahder, P. W. U. Appel, and G. Asmund, "Mercury in soap in Tanzania," Tech. Rep. 306, 1999, Copenhagen, Ministry of Environment and Energy, National Environmental Research Institute (NERI).

[22] E. Uram, B. P. Bischofer, and S. Hagemann, "Market analysis of some mercury-containing products and their mercury-free alternatives in selected regions," Gesellschaft für Anlagenund Reaktorsicherheit (GRS) mbH GRS-253, 2010. 


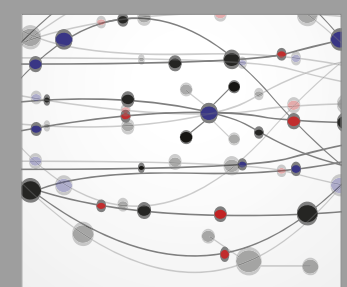

The Scientific World Journal
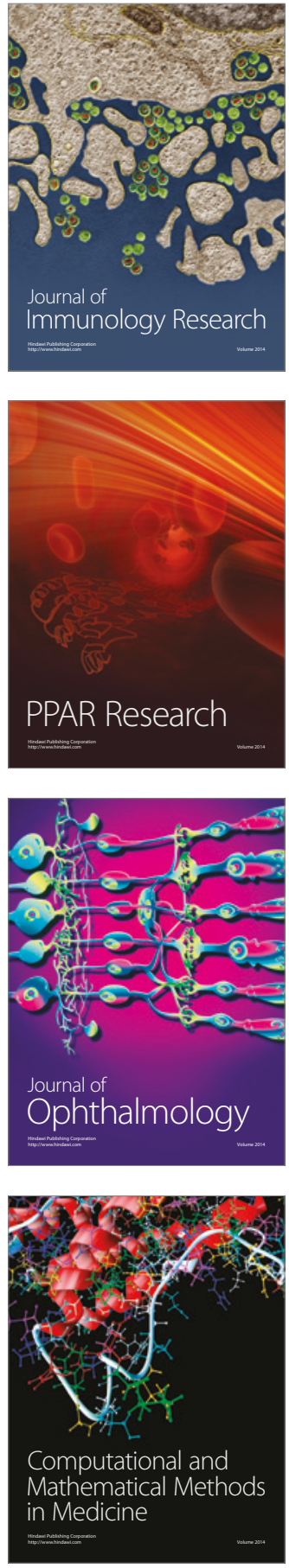

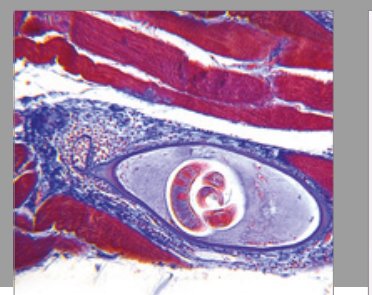

Gastroenterology Research and Practice
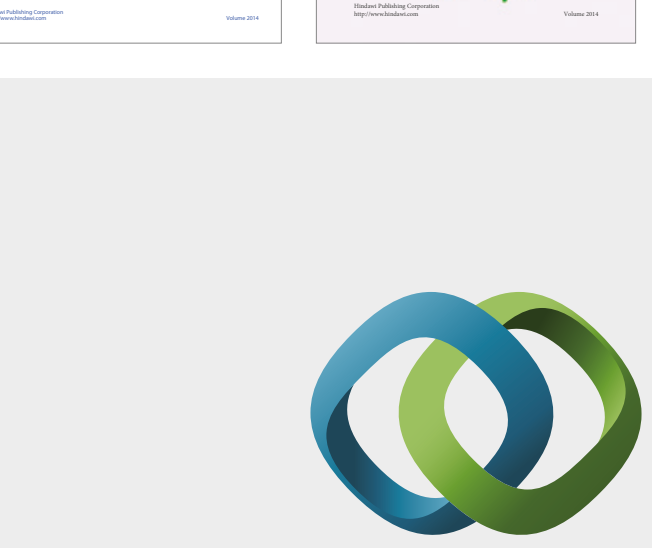

\section{Hindawi}

Submit your manuscripts at

https://www.hindawi.com
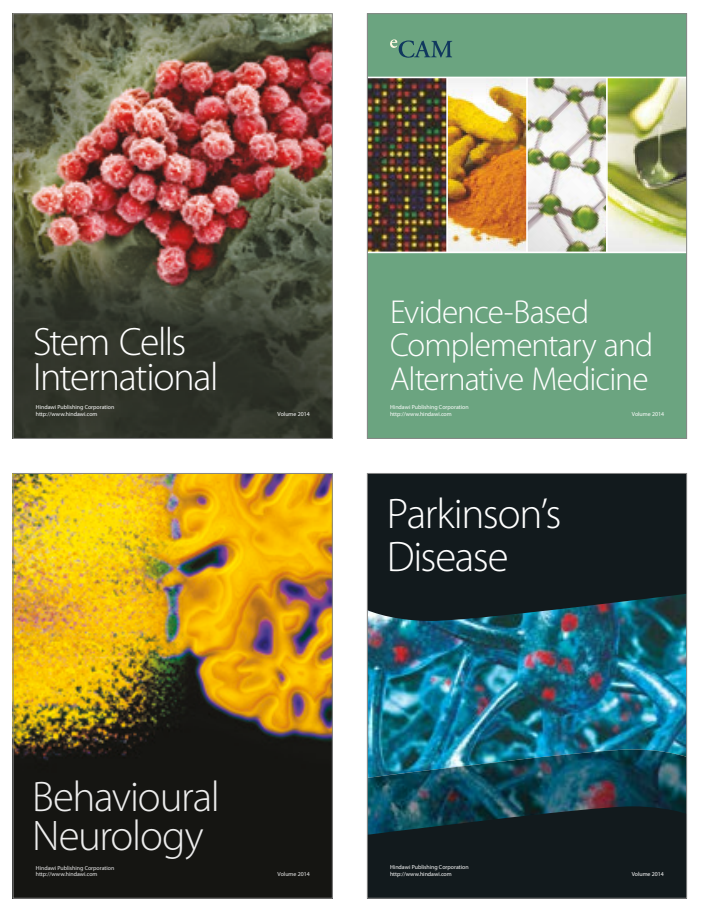
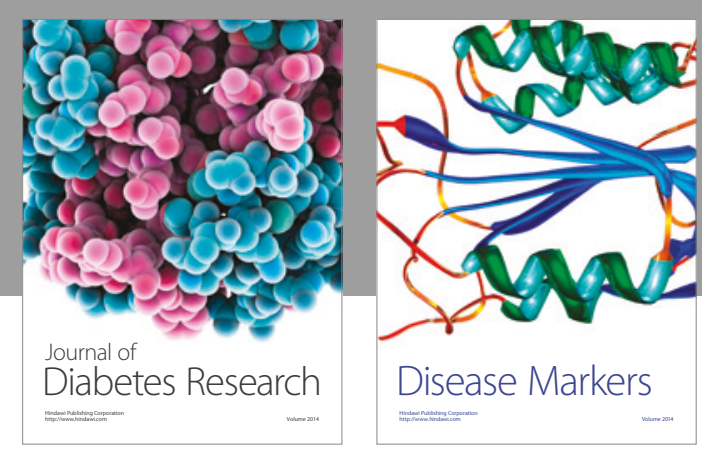

Disease Markers
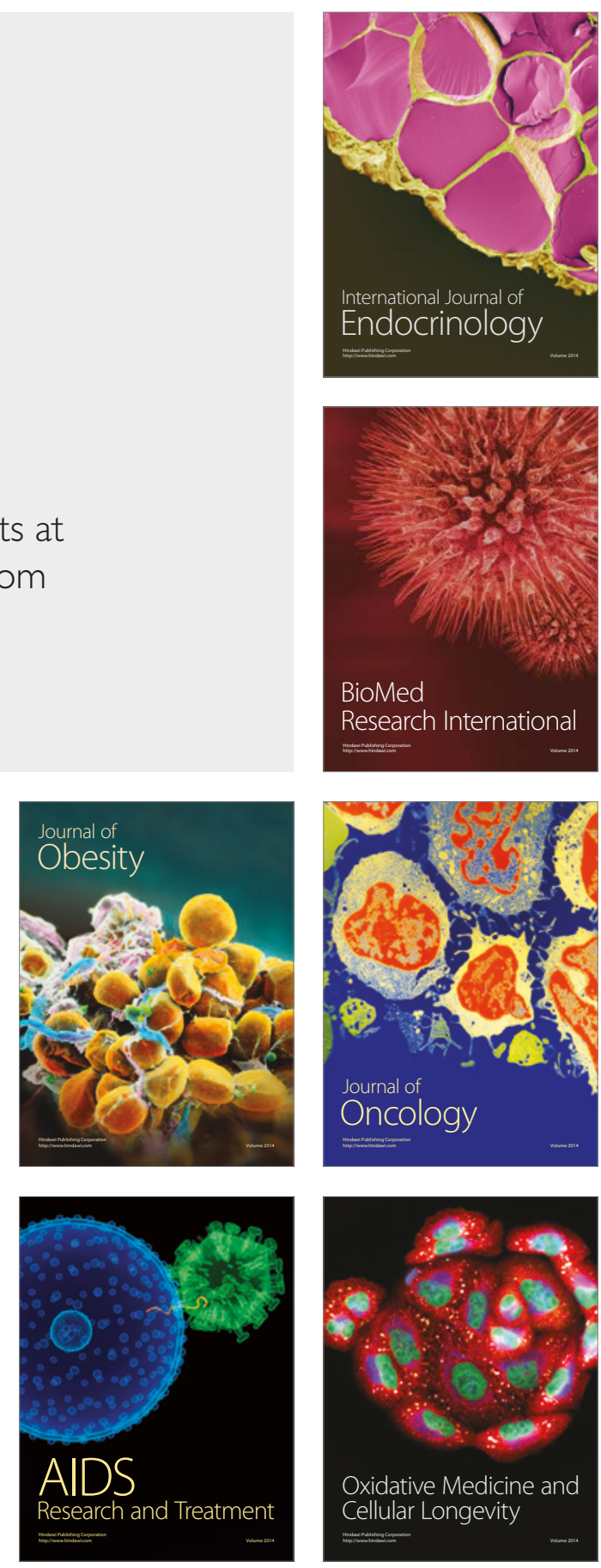